\title{
Socio-psychological Portrait of the User of New Media on Example of Participants MMORPG "World of WarCraft and LineAge"
}

Evgenia Yurevna Kiyashko1

Egor Borisovich Marin²

Tatiana Aleksandrovna Vasilieva ${ }^{3}$

1 Vladivostok State University of Economics and Service

2Maritime State University named after Admiral G.I. Nevelskoy

${ }^{3}$ Far-Eastern Federal University

Email: Evgeniya.Kiyashko@vvsu.ru

\section{Doi:10.5901/mjss.2015.v6n3s6p269}

\section{Abstract}

The article is constructed social and psychological portrait of the new media users, including members multiplayer online role playing games in Russia. It is alleged that the massively multiplayer online role-playing game (hereinafter - MMORPG), as a new media, provide unlimited possibilities for individualization of messages participants MMORPG, while enabling simultaneous mass exchange. In the context of the information society in Russia today is the formation of communities of users of various new media. This phenomenon remains virtually unexplored. The article summarized and systematized the results of research conducted by the authors in 2014 on the theme: "Social and psychological profile of users (for example members MMORPG" World of WarCraft and LineAge ")". The study authors were able to give a generalized social and psychological characteristics of groups of users of new media in Russia, for example community of online game "World of WarCraft and LineAge".

Keywords: information society massively multiplayer online role-playing games, new media, role-based community, social and psychological portrait.

\section{Introduction}

In today's Russian society, in terms of information technology development in the last two decades of the twenty-first century, there is a rapid formation of a new type of society, which is called information. Technological innovations have become an integral part of the existence of society, significantly affecting all aspects of his life (Kononova O., Yakimova Z., 2013). The ubiquity of new media (blogs - "Live Journal"; social networks-Facebook, Instagram; miry- virtual "Second Life") led to the formation of a new species of Culture - "digital culture" (Kirsanova L., Korotina O., 2014). The social consequences of the structural features of the new media distinguish new media from interpersonal and mass communication channels (Crosbie V., 2009). Currently, the new media are described by features such as a digital nature, individualizirovannost messages virtuality, interactivity, "a combination of many to many" (Manovich L., http://andreknoerig.de/portfolio/03/bin/resources/manovich-langofnewmedia.pdf., 2012). As a result, the spread of new media made possible the gap between the living body, body image and a digital representation of the body, which can take a brain (Camper D., 2010).

There is now a whole range of research approaches to understand the personality (biological, sociological, individual psychological, social and psychological). In our research, the determining factor is the socio-psychological approach the study of personality. In the scientific literature decided to allocate "live action role-playing game" and "massively multiplayer online role-playing game (hereinafter - MMORPG)." Massively Multiplayer Online Role-Playing Game (MMORPG) is a special online game allowing hundreds or thousands of geographically distributed players to simultaneously play on the internet (Barnett \& Coulson, 2010). MMORPG is composed of solo play and collective play (Taylor T., 2006). Solo play is the experience that an individual plays all by himself / herself, exploring the virtual land, killing monsters, progressing toward higher positions, without collaborating with other players. Collective play often takes on the forms of guild-play and group-play (Murphy S., 2007; Taylor T., 2006) in which an individual collaborates or interacts with other players.Suschestvuet one game server on which the database the players and the game world. Upon 
entering the game client connects to the server, allowing the player to interact with other players, to connect to the same server. Thus, a sort of web, the center of which is the server, and lines are drawn to it by customers. All advance in the game is automatically saved on the server. Most of these games are beautifully decorated, have attractive graphics and good music. The basis of all games online - raising and skills of your character, who with each level getting stronger and stronger, and giving confidence to the player. While traveling through the game world players often meets other player characters. Here begins the most important difference from the usual MMORPG games. Interaction with other players can be varied from harmless greeting to instant attack. "World of WarCraft and LineAge" - two of the most popular online games in the world.

\section{Literature Review}

The theoretical basis of the study were the concepts and theories of subculture, the theory of the information society M. Castells (Castells M., 1998), Sociological Theory of virtual reality models A. Bul, D. Bell and J. Masuda (Masuda Y., 1981), the theory of the "Internet -dependence "(Goldberg I., 1999).

In the study of the phenomenon of role-playing games in Russia, in the humanities a long period of time was dominant subcultural approach. Under this approach, the consortium participants role-play is defined as a subculture. In this connection it may be mentioned collection, released in 2009 by the publishing house of the RAS under the name "Youth Subcultures of Moscow" (Gromov, 2009). Currently, the community role to interpret, there is another approach that the transformation of the community role of subcultures in the cultural mainstream (Müller M., 2011). One of the authors of this approach is D. Hebdaydzh (Hebdige D., 1979). The main argument in favor of this opinion is the statement that for the last 10 years the world has seen the erosion of the characteristic features of the subculture of role the community, the commercialization of the scope of role-playing games. Role-based community of recent years is no longer a marginal group, and recognized part of society.

Theory of Internet addiction. For the first time on the issue of excessive use of the Internet began to speak abroad in the late 80s. Twentieth century. A quantitative analysis of the Internet depending spent Orman (Internet Stress Scale (ISS)). Qualitative analysis of Internet addiction in the 90s of the twentieth century spent A. Goldberg. He introduced into scientific circulation the term "Internet addiction" Goldberg Internet Addiction Disorder scale (GIAD) (Goldberg l., 1999). According to his theory of internet addiction - this morbid, irresistible urge to use of the Internet, has a negative impact on the consumer, labor, social, family and financial spheres. A particular manifestation of Internet addiction is dependence on the multiplayer online role playing games. MMORPG users show more often problematic gaming behavior, depressive tendencies and lower self-esteem compared to users playing other online-games. MMORPG users reported to playing significantly more often in order to escape from real-life problems, which might be a valuable coping strategy but might also lead to problematic gaming behavior (Birgit et al., 2011).

After what happened in the twentieth century. another technological revolution in scientific discourse firmly established the concept of "information" and "information society" (Mordovtsev A.Yu., Mordovceva T.V, Mamychev A.Yu., 2015). The term "information society", still does not have a generally accepted definition. The approaches to the definition of the concept differs depending on the context of use. Initially, the terminology and the concept of the information society have been formulated - F. Machlup, Umesao T., Y. Hayashi. "The Information Age, which brought with computer technology and means of communication, not only will have a major socio-economic impact on modern industrial society, it would entail the social changes of this magnitude that will cause the transformation of modern system in a completely new type of human society, that is, in the Information Society "(Masuda Y., 1981). Thus, the work of the first researchers of the information society were focused primarily on the study of "capitalization of knowledge and education," the development of high technologies in a particular historical situation.

The development of the information society is conceptually and practically means the formation of the global information space. The main distinguishing feature of this space is the formation of information communications, allowing access to any type of data anywhere at any time.

Computerisation of everyday life brings into use virtual reality as computer simulations of real things and actions. The depth of penetration of virtuality in social and individual life suggests the "virtualization" of society. The term "virtual reality" is used in the broader context of the description of the new phenomena such as the "virtual bank", "virtual corporation" "virtual court", "virtual studio", "virtual money". Today, with the Internet you can buy intellectual and material goods in your store; making money by taking and placing advertising on virtual billboards, winning in a virtual casino, play on virtual exchanges, participate in virtual workshops, conferences, become a member of a virtual club communities; You can even create love and family. These and other virtual equivalents of real interaction leads to the replacement of the actual performance of social roles, simulation, creating the image of the "real attributes of institutionality." 
With the development of information networks, linking people space - disunity, there is a change notions of space and time. About compression "time - space" in contemporary society, Manuel Castells wrote, describing this phenomenon is through the concept of "timeless time", stressing that the networked society creates an "eternal universe" in which the limitations of time and space will be more leveled. The concept of the network society, was represented by M. Castells in "The Information Age: Economy, Society and Culture" (Castels M., 1998), in which he called the network key to the development of society, it is a network and makes it possible to communicate interactively communicate with anyone anywhere. The benefits of network communication is the ability to bring people together in one particular place, and complex buildings, the national computer network.

Recently actualized the issue of the impact of different symbolic realities on human consciousness as individuals and as members of society, the formation of his personal world view (Mamychev A.Yu., Kiyashko E.Yu., Timofeeva A.A., 2015).

The phenomenon of virtualization of the social reality of the consumer society in the aspects examined by $\mathrm{J}$. Baudrillard, noting that "the perspective of social space comes to an end. There is a blurring of the boundaries between reality and artificial world." Jean Baudrillard uses the term simulacrum (Baudrillard J., 2000) and proves that man today does not deal with reality and hyperreality (superreality, virtual reality), in which the world is perceived as a flow of information. Dangers virtualization Culture Jean Baudrillard saw in the failure to distinguish genuine and artificial reality.

Analysis of the socio-psychological aspects of construction of social reality made Berger P. and T. Lukman. "Higher reality surrounds them on all sides, and consciousness always comes back to reality as the highest of the tour ...". "There is a" switch "from the world of everyday life in the world of the game, how to play both children and adults. A brilliant illustration of this game - the theater. The transition from one to another reality is marked by the fact that the curtain is raised and lowered. When the curtain rises, the viewer is "transferred" to another world with its own values, and the device does not have anything, or, on the contrary, have much in common with the device of everyday life. When the curtain falls, the audience "back to reality", rather, to the ultimate reality of everyday life, in comparison with which the reality presented on stage now seems insignificant and ephemeral, however alive any idea a few minutes ago" (Berger $P$. \& Lukman T., 1995).

Virtualization society, the spread of the Internet has led to the emergence of new social structures, especially various network communities, the construction of which, as a rule, ignored the social structure of society. Network society creates a horizontal network structures, their virtual space, the reality with his management technologies, in some cases, reducing the importance of the traditional focus on government institutions of society.

The massively multiplayer online role-playing game (MMORPG hereinafter) involved all social strata and age cohort of the population. The purpose of this study, the participants identify personal characteristics MMORPG and make their social and psychological portrait. Under the socio-psychological portrait of members of the new media, in particular members MMORPG, we understand - a comprehensive description of the person, containing a description of its surrounding and inner peace, and possible actions in certain situations.

\section{Methods and Materials}

In a study in the September-October 2014 were interviewed 58 respondents. Of the 58 respondents 15 men, 43 - women. Most of the respondents were aged 20-30 years, 35 people from 16-19 years, 14 people., 30-43-9 people.

Methods for gathering information - in the form of a questionnaire survey and interviews. In conducting interviews of massively multiplayer online role-playing games happening asymmetric communicative interaction, characterized by lack of communication-privileged roles in interviewer. All participants have the same opportunities of communication to speak. This type of building relationships in the course of interviewing participants in massively multiplayer online roleplaying games, will create conditions informal conversation. The basis of the study was the method of in-depth interviews as well as a mobile poll (cellular, video, e-mails, if different time zones, or employment of the respondents). To conduct the survey questionnaire was developed, which includes 20 questions. After filling the questionnaire with respondents conducted in-depth interviews.

The questionnaire consisted of two parts. The first part of the questionnaire consisted of questions 1-14, the answers to which allowed determining the attitude of respondents to the role-playing game and its possibilities. The second part of the questionnaire contained questions 15-20 - questions for users of the new media, in the reply which reflected the personality characteristics of respondents. 


\section{Results and Discussion}

\subsection{Socio-demographic characteristics of the community}

The majority of respondents (41 people) - Residents of the municipal urban district of Vladivostok, nine respondents in cities of federal significance Moscow (3 people) and St. Petersburg (6 pers.), And two respondents from the town of Essentuki, Barnaul, Baku, Saki (Crimea), only 8 people, living in different cities and living in different time zones with different social status, perform different social roles.

Among the respondents, most - people, non-manual workers. When asked about the kind of activity 21 respondents indicated that they are students of higher educational institutions (student, graduate student), thirteen respondents indicated that they are qualified, ten respondents chose option - unemployed / housewife / householder, one - directed by one the respondent stated that he soldier, four respondents selected position - manager, eight respondents indicated position - a person with disabilities. According to poll results, MMORPG are an integral part of life of people with disabilities as being in an enclosed space (house, apartment) they did not have the opportunity to enjoy a full life, to communicate, getting into virtual reality "pushing the boundaries of reality," they discover new features. For people with disabilities virtual environment - a safe haven, making it possible to realize their desires and capabilities.

\subsection{Personality characteristics of participants MMORPG}

Based on the analysis of questionnaires and interviews, we have tried to reconstruct the personality traits peculiar to the participants role-playing online games. These personality traits are reflected in the respondents' answers. "Pushing the limits of reality, I find freedom," "The game is released on the norms and values of the traditional culture of society, from social, political and even biological constraint." Most respondents indicate emotional poverty, inferiority of modern society. We entered the age of "spectacles" (F. Webster, 2004), when a person becomes aware of the unreliability of signs, from which he creates himself, "There, in the game I can be whatever I want," "There, I'm playing the role of the courtesan, what in my life I will not let myself".

Getting used to life in the virtual world is like a pathological desire to gamble. One means of escape from reality, in the information society began to computer games.

According to respondents, the characteristic feature of the virtual world is its flexibility, being in a virtual reality, you can manifest itself in different roles: soldier, miner, hunter, knight, Amazon, etc. The most informative in our study were the answers to two questions - why you are part of a role-playing community and apply whether you are in life and helps you develop your personal method of changing roles. Here are the most interesting answers to these questions.

When asked why you are part of role-playing community, we obtained the following answers:

1. "I like to transform into other characters, see yourself a different person, I love the scene".

2. "The people who were involved in role-playing activities are very interesting and versatile. I find it interesting to spend time in their circle, like to invent something new, to try on different roles".

3. "Because everyone in this community has a role, the performance of which is due to the behavior in everyday life. In other matters, and the choice of this role in our community depends solely on behavior and personal qualities of the participants".

4. "I'm close to the ideas, goals and objectives of the community. This fascination promotes self-development, increases the circle of acquaintances, promotes productive leisure, social adapt".

5. "Because I like to transform into a human / nonhuman other periods / worlds. I find it - it is very entertaining and relaxing pastime".

6. "Provides ample space for creative self-realization".

7. "I love unusual beautiful costumes and socializing with new people. And also I love the work of science fiction, of course."

8. "In this environment, I'm comfortable. It helps to learn to interact with others".

9. "Distract from the problems, provides an opportunity to find a good company, to meet new people, get positive emotions".

10. "Passion certain fendomom to such an extent that there was a desire to apply to itself the role of character you like".

11. "Because I like and chat and emotions and, in part, to fulfill their potential".

12. "Over time, role-based community has been an integral part of my life".

13. "In some aspects of life lack the freedom that exists in role-playing games within each character. Just 
interaction with many people it is impossible because of the distance and their own isolation, due to the peculiarities of character".

14. "It's interesting, unusual. And since I'm a creative person, I love the theater in the broadest sense of the word, I like to try on different roles, be yourself, play other people, other times, other universes. It all starts with the words: "And what happens if I ..." and went".

15. "For me it is a way to obtain life experience, a way to get the missing in real life - and in terms of the events I emotions, and in terms of communication with interesting people in my world".

16. "Out of habit, 18 years as the role players".

17. "Because it was his party as a teenager and since then he saw no reason to change something in my life".

Thus, the respondents' answers show that participation in web community has become for them an integral part of life. This participation allows them to experience new emotions, to realize the creative potential, to find a new channel of communication. There is a huge choice of virtual space: "Once in the game, I realize how many impediments gone out of my way. I'm tempted, tempted to stay in this ideal world for me". There is a change of an individual's self-awareness and its role in the real and virtual world. Some respondents noted that it is easier to discuss sensitive issues with their online friends because of anonymity on the Internet. This feature of the online interaction previously noted by other investigators (McKenna, et al., 2002).

Does your personal development method of "role reversal"? Do you use this method of "outside" the circle of the dialogue, in real life?

1. "Yes, sometimes, but not in some global scale, because all of my roles - the brink of my own personality. Develop or that its role as a replacement part helps. But most still recognize them and for the benefit of all to exploit".

2. "Adapting in the virtual space, some communicative side of the individual, responsible for the socialization, develop, and is of forum games. The method of "role reversal" in real life do not apply".

3. "Often I catch myself on the fact that many of the problems by analyzing a person of his character. As if he did, what he was doing in a given situation. Because of my role - is most often the role of a strong and internally open-minded people, this mask is sometimes very helpful if not solve the problem, it is easier for her to take".

4. "It helps to consider the hidden facets of my character, but I try not to use like this in real life, because I do not believe it (life) game and I want to stay out of this game, and for what is".

5. "Do not try. I doubt that it can somehow impact on my life. Staying themselves and to engage in selfdevelopment - that's the main thing".

6. "It is possible and helps. I myself say exactly nothing about it can - only people who know me well enough from the outside, can appreciate my development".

7. "I have never considered the" role change "as the motivation for personal development. For me, role-playing games - a leisure activity, in real life I do not apply".

8. "Each role model specific character somehow imposes a mark on the person. Skills obtained in the course of development "roles" is applied in real life, but I remember and what I said intelligent man Stanislavsky "leaving the theater, do not forget to get out of role".

9. "It helps. So I can better understand the motivations of others. Method apply in real life, it was easier to talk to strangers".

10. "Do not change the role of practice in the real / everyday life".

11. "Role change must be due to a necessity. If such a need exists - and "change roles" will, for example, to solve the problem, I will definitely take advantage of it, taking the qualities, in normal circumstances, I do not peculiar. In general, this method can help find a way out of situations where I was in my usual role for what could not have done".

12. "Yes. This method helps to find a poorly developed and the quality evident in any character, which I have to play".

13. "It is often use "change roles "adjusting to the person on their studies, home, etc. Naturally, the method works".

14. "I do not know if it helps the development, but often try on the role of the outside circle of friends".

15. "Of course applies very helpful, especially when it comes to giving up bad habits, which was used in the normal rhythm of life".

Thus, the role-playing games are a means of self-development, the acquisition of new experiences. For half of the survey participants tend to use the change of roles in real life. Another part of the participants do not practice the transfer of experience role reversal from the game in real life. 
These responses and other materials interview allowed us to identify a number of typical community member's motives and personality traits. The main motivations to participate in role-playing games are:

- gaming motifs (passion gameplay);

- $\quad$ the desire to implement the craving for freedom;

- $\quad$ uhod from reality, the freedom to choose whom to be in the game;

- avoiding the stressful effects;

- $\quad$ the desire for emancipation;

- Communication.

The study highlighted a number of social and psychological problems of the participants MMORPG: limiting social relationships, contacts and lack of access to participation in public life. This, above all, the lack of full participation in the civil society, satisfaction of personal interests. For many participants tend to the pursuit of creative activity, of selfrealization. One aspect of the community members online role-playing games is the structure of the collective creativity. "By creating your personal world, populate it, I watch him, I think over the script, contemplate their real life experiences, gather yourself again and again," "Striving for self-expression in the game, develop their imagination and creativity. In real life, it helps me to do what he likes - I'm a blacksmith, no, not by profession. This is my hobby".

It should be noted that the virtual reality craze can contribute to both social adjustment and maladjustment. Social adaptation can occur due to compliance with social standards, as well as through the acquisition of new experiences. Young people do not use new media falls out of his familiar circle of forms of communication.

\section{Conclusion}

Based on these results we were able to construct a general social and psychological portrait of the users of the new media, in particular members MMORPG. It includes the following socio-demographic and personality characteristics.

Based on questionnaires and interviews revealed the main motivations to participate in the MMORPG. These reasons include, first of all, the desire to improve self-esteem, to realize the freedom of choice of social roles, to get away from the stresses and contradictions of real life. Tools of the new media are neither good nor bad for the individual and society. From a social and psychological point of view, they can be assessed as neutral. Use of new media, can both contribute to the realization of social needs, personal development, and lead to destructive consequences for the individual, such as Internet addiction. The desire for personal development and the formation of new social skills development that occurs in the game. For many participants tend to creativity in the individual. Game - is the realization of creative potential. For the participants of the role-playing online games in real life the disadvantage interesting dialogue, limited contacts. This is typical for persons with disabilities.

As we have seen, one of the characteristics of users of new media is quite a high proportion of them composed of persons with disabilities. For them, the virtual environment - a refuge from the contradictions of real life problems, while tool compensation is not implemented socio-psychological and physiological needs.

The results showed that the multiplayer online role playing for most of the participants have become an integral part of life. Games unite people of different social status of society, age, place of residence. For the participants of the online games have become a tool offset their disability. The common thread was the desire to unleash your creativity, reveal the social circle, not previously disclosed to implement the part of your personality. The main factors MMORPG hobbies are: imagination, curiosity, acceptance by the players of the guild. Making social and psychological portrait of members of the new media, in particular members MMORPG needs a more detailed theoretical analysis and methodology. MMORPG study the influence on the socio-psychological characteristics and adaptation of persons with disabilities.

\section{References}

Berger, P. \& Lukman T. (1995) The social construction of reality. A treatise on the sociology of knowledge. M. Castells, M. (2000), The Information Age: Economy, Society and Culture. M.

Castells, M. (2000). The information age: Economy, society and culture. (2nd ed.). Cambridge, Mass.: Blackwell.

Touraine, A. The waning sociological image of social life // International journal of comparative sociology - Vol. 25 (1984), - \# 1-2.

Webster, F. (2004) Theories of the information society. M.

Jean, Baudrillard (2000) Symbolic exchange and death. M.

Camper, D. "Body of abstraction" of the anthropological quadrilateral space, surfaces, lines and points. St. Petersburg.

Crosbie, V. What is New Media? / V. Crosbie/l Sociology.org.uk. - Electronic text data. - Mode of access: www.sociology.org. uk/as4mm3a.doc. - Title from screen. 
Gromov D.V. (2009) Youth subcultures Moscow M.

Barnett, J., \& Coulson, M. Research from Middlesex University in the area of general psychology published. (2010, July 24). Psychology \& Psychiatry Journal.

Birgit, U. Stetina, Oswald D. Kothgassner, Mario Lehenbauer, Ilse Kryspin-Exner (2011) Beyond the fascination of online-games: Probing addictive behavior and depression in the world of online-gaming Computers in Human Behavior, Volume 27 , Issue 1.

Goldberg, I., MD Web Publishing 1996-1999

Hebdige, D. (1979). Subculture, the meaning of style. London: Methuen.

Kirsanova, L., Korotina, O. (2014) On the Contents of the Protest Conscience in Russia. Wolrd Applied Sciences Journal 31(5)

Kononova, O., Yakimova Z. (2013). Competence as an object for Assessmen and Measuremen in Training Quality Control System//World Applied Sciences journale. T.27.

Mamychev, A.Yu., Kiyashko E.Yu., Timofeeva A.A. (2015) Conservative political transformation projects of Russian power: the main discourses of modernity // Mediterranean Journal of Social Sciences. Vol. 6, № 3, May 2015. Supplement 2.

Manovich, L. The Language of New Media. Available at: http://andreknoerig.de/portfolio/03/bin/resources/manovich-langofnewmedia.pdf. Masuda, Y. The Information Society as Post-Industrial Society. Wash., 1981.

Mordovtsev, A.Yu., Mordovceva T.V., Mamychev A.Yu. (2015) Convergence of law: the variety of discourses // Mediterranean Journal of Social Sciences. Vol. 6, № 3, May

Müller, Maya, From Subculture to Mainstream (2011) // Think Larp - Academic Writings from KP2011, First Edition.

Murphy, S. M. (2007). A social meaning framework for research on participation in social online games. Journal of Media Psychology, 12(2).

Taylor, T. L. (2006). Play between worlds: Exploring online game culture. Cambridge: MIT Press.

McKenna, K., Green, A. S., \& Gleason, M. E. G. (2002). Relationship formation on the internet: What is the big attraction. Journal of Social Issues, 58(1). 
